\title{
Examining the Relationship between Referee Self-efficacy and General Self-efficacy Levels of Football, Basketball and Handball Referees
}

\author{
Aydın Karaçam ${ }^{1, *}$, Atilla Pulur ${ }^{2}$ \\ ${ }^{1}$ Ministry of National Education, Turkey \\ ${ }^{2}$ Faculty of Sport Sciences, Gazi University, Turkey
}

Copyright $\bigcirc 2017$ by authors, all rights reserved. Authors agree that this article remains permanently open access under the terms of the Creative Commons Attribution License 4.0 International License

\begin{abstract}
The aim of this study is to examine the relationship between referee self-efficacy and general self-efficacy levels of football, basketball and handball referees in terms of gender, refereeing branch, age and refereeing experience. Study group was created within a convenience sampling method. 195 referees, $14 \%(n=27)$ female and $86 \%(\mathrm{n}=168)$ male, who perform active refereeing within Turkish Football, Basketball and Handball Federations during 2016-2017 season participated in the study. The personal information form, Referee Self-Efficacy Scale (REFS) developed by Karacam and Pulur (2017) and the General Self-Efficacy Scale (GSE) developed by Aypay (2010) were used as data collection tools. The analysis of the data was conducted using SPSS 21 and AMOS programs. Pearson Product Moment Correlation Coefficient, t-test and one-way variance analysis (ANOVA) were used in determining the relationships between variables, binary and multiple comparisons, respectively. The REFS total scores levels of football, basketball and handball referees show a significant difference in favor of male referees. A significant difference was found between REFS total scores levels of football, basketball and handball referees and physical fitness sub-dimension, and refereeing branches in favor of football and basketball referees. There is a positive and significant relationship between football, basketball and handball referees' game knowledge, decision making, pressure, communication, total scores in REFS, and refereeing experience. There is a positive and significant relationship between football, basketball and handball referees' physical fitness, game knowledge, decision making, pressure, communication, total scores in GES and REFS.
\end{abstract}

Keywords Referee Education, Referee, Self-efficacy, Referee Self-efficacy, Football Referee, Basketball Referee, Handball Referee

\section{Introduction}

Referee self-efficacy was conceptualized within self-efficacy theory of Bandura [1], and specifically self-efficacy in sports [2]. When certain situational demands are considered, self-efficacy can be defined as one's belief to accomplish behaviors resulting in desired consequences in a certain condition and ability to perform various levels of a task successfully [3-4].A strong self-efficacy provides achievement and well-being, and varying in personal development and capabilities. The one who has a strong self-efficacy is able to focus on achievement by recovering himself and changing his strategy without attributing the failure to totally himself [3-4-5].

Referees should perform and accomplish more than one task during a competition under pressure in order not to make a mistake in their decisions. For example, under adverse conditions and pressure, referees should analyze and judge the events during the match, make quick decisions, referee the match, consider more than one dimension of the match, maintain the order and settle the disagreements [6-7]. Inefficacy, carelessness, wrong decisions, delayed responses in these tasks may result in an ultimate stress and burnout [8-9].

In the sport psychology field, many studies indicate that self-efficacy belief is important for athletes [10-11-12-13], teams [14-15-16] and coaches [17-18]. Improvements in related studies of each of these certain groups resulted in significant conceptual developments [19-17-20-21] and certain measurement models [17-22]. However, Guillén and Feltz [8] indicated that referees can be considered as an important group of people who are mostly ignored in terms of their self-efficacy beliefs towards refereeing performance. For this reason, it was stated that conceptual and measurement models are needed to guide the studies in this field. 
Referee self-efficacy was defined as the extent of belief that referees have an adequate capacity to accomplish their tasks successfully [8]. Guillén and Feltz [8], Myers et al. [23] and Karaçam and Pulur [24] stated that referee self-efficacy is composed of game knowledge and strategic skills, decision making skills, psychological skills, in-game interaction - supervision and physical fitness factors. Based on the self-sufficiency theory and studies of self-efficacy in sport, Guillén and Feltz [8] stated that referees whose self-efficacy is high take truer decisions, show more effective performance and show more commitment to their jobs. Moreover, it was stated that they are shown respect more than coaches, managers and other officials; and they experience less stress than the ones who have lower self-efficacy. Besides, Guillén \& Feltz [8] and Farshad et al. [25] stated that the referees having higher self-efficacy are more committed to their job and this effects their performance positively. In a study conducted by Hepler and Feltz [26], self-efficacy level has an important impact on decision making. By the way, Myers et al. [23], Karaçam and Pulur [24] and Karaçam and Pulur [27] concluded that referees' physical fitness, game knowledge, decision making, pressure, communication, referee self-efficacy and general self-efficacy effects each other positively. Moreover, Myers et al. [23], Karaçam and Pulur [24-27] found a positive correlation between self-efficacy levels of referees and their ages and refereeing experience and stated that self-efficacy levels of referees increase as their age and refereeing experience increase.

Each sports branch has its own physical fitness, psychological pressure factors, game structure and strategies. The referees should know the characteristics of the branch in which they referee and prepare themselves accordingly. Referees should evaluate the actions during the match and judge, make quick decisions, referee the game, communicate correctly, pay attention to multiple aspects of the game, maintain the order, and resolve conflicts and problems under adverse conditions and pressures in their own branches [6-7]. Referees in the football branch are subject to high level physical load, and spectator, player and club pressure for ninety minutes. In addition, football referees are brought under pressure from fan groups and media even after the match due to the popularity brought by the branch. Basketball referees must manage a very fast-paced game where there is too much contact in a narrow area. Mostly, they must make instant decisions and run faster than the players by refereeing mechanics. The basketball referees are kept under pressure by spectators, players, teams and managers before and after the match in the basketball game with the increase of popularity in the recent years although to a lesser extent of football. Handball referees also must manage a game that is played in a narrow area, has a lot of contact, and where the physical power is on the forefront. Even though it does not have as much popularity as football and basketball, the pressure of the teams makes them hard to do. For this reason, it is very important to know the level of self-efficacy and general self-efficacy of the referees who work in football, basketball and handball branches to raise the referee performance to the upper level.

Although studies on referee self-efficacy and general self-efficacy levels are scarce, the development of referee self-efficacy and general self-efficacy perceptions of basketball referees is crucial in the successful refereeing the competitions. Furthermore, it is very important to know the variables effecting the referee self-efficacy and general self-efficacy perceptions of the basketball referees and the relationship between these variables in planning the referee's training process and raising the referee's performance. In this context, the following questions will be answered in the research.

1. Do referee self-efficacy and general self-efficacy perceptions of football, basketball and handball referees show a significant difference based on the variables of gender and refereeing branch?

2. Is there a significant relationship between referee self-efficacy and general self-efficacy perceptions of football, basketball and handball referees and age-experience variables?

3. Is there a significant relationship between referee self-efficacy and general self-efficacy levels of football, basketball and handball referees?

\subsection{Self-Efficacy}

The concept of self-efficacy was proposed by Bandura [3]. According to Bandura [3], self-efficacy is the belief that a person can successfully perform his or her behavior to get the desired results. In other words, self-efficacy is the belief about himself/herself as to how successful an individual can be to overcome difficult situations in the future. Self-efficacy is the one's self-judgment on his/her ability to cope with different situations, achieve a certain activity, and his/her capacity [28]. Social cognitive theory implies that self-efficacy belief plays a strong role in human behavior. Self-efficacy belief does not depend on one's abilities, but one can believe that they can accomplish a job by believing their abilities. These beliefs influence action plans of the individual [29]. Self-sufficiency is considered to be a variable that directly affects the behavior of individuals [30].

\section{Materials and Methods}

In this section details are given related to characteristics of the study group, data collection tools and data analysis.

\subsection{Research Model}

The aim of this study is to examine the relationship between referee self-efficacy and general self-efficacy levels of football, basketball and handball referees in terms of gender, refereeing branch, age and refereeing experience. The study is a descriptive study with relational survey model. 
Although relational research does not prove the existence of causality in a real sense, it is possible to make inferences about the cause-effect relationship with relational investigations by using some advanced statistical techniques [31].

\subsection{Study Group}

The study group was formed by convenience sampling method in this research. A convenience sampling method based on accessibility and availability principles is the mostly preferred method in some research subjects to gather information quickly [32]. 195 referees, $14 \%(\mathrm{n}=27)$ female and $86 \%(\mathrm{n}=168)$ male, who performed active refereeing within Turkish Football, Basketball and Handball Federations during 2016-2017 season participated in the study. Of these referees, $50 \%(\mathrm{n}=99)$ is football, $29 \%(\mathrm{n}=$ $56)$ is basketball and $21 \%(n=40)$ is handball referee. The average age of the referees participating in the research is 26 , and the average of refereeing experience is 5 years. In this study, the application of the data collection tool was implemented one day when the referees did not have a competition, considering the voluntariness principle.

\subsection{Data Collection Tools}

Referee Self-Efficacy Scale (REFS) and General Self-Efficacy Scale (GSE) were utilized to determine referee self-efficacy and general self-efficacy levels of football, basketball and handball referees.

\subsubsection{Referee Self-Efficacy Scale (REFS)}

Referee Self-Efficacy Scale (REFS) was firstly developed by Myers et al. [23] in 2012. Turkish adaptation of the scale was conducted by Karaçam and Pulur [24]. The scale has 18 items which were created in five point Likert grading format. In the scale, there are 5 sub-dimensions as physical fitness which is composed of 5 items (sample item: Have a physical fitness which is fit to refereeing), game knowledge which is composed of 3 items (sample item: I am able to understand all the rules of your sport), decision making which is composed of 3 items (sample item: I am able to make quick decisions), pressure which is composed of 3 items (sample item: I am not uninfluenced by pressure from coaches) and communication which is composed of 4 items (example item: I am able to communicate effectively with other referees). Grading options of the scale items are indicated as "Strongly disagree $=1$ " and "Strongly agree $=5$ ". There is not any item that is reversely scored. High scores that are obtained from each factor of the scale indicate that self-efficacy is high in that factor. In the analyses conducted by Karaçam and Pulur [24], the variance explained for the whole scale was found to be $72.27 \%$. A five-component structure with an eigenvalue greater than 1 has emerged. For the scale components, alpha internal consistency coefficients were found to be .88 in physical fitness factor, .71 in game information factor, .85 in decision factor, .88 in pressure factor, .81 in communication factor and .90 in total communication scale. The KMO value was found to be .86 . As a result of DFA analysis applied to the scale, it was seen that $\chi 2 / \mathrm{sd}=1.842 \mathrm{RMSEA}=.06$, CFI $=.94, \mathrm{GFI}=.88, \mathrm{RMR}=.01$.

In the conducted for this study, the variance explained for the whole scale was found to be $71.18 \%$. A five-component structure with an eigenvalue greater than 1 emerged. For the scale components, alpha internal consistency coefficients were found to be .87 in physical fitness factor, .77 in game knowledge factor, .80 in decision making factor, .88 in pressure factor, .80 in communication factor and .90 in total scale. The KMO value was found to be .88 . The DFA analysis of the scale showed that $\chi 2 / \mathrm{sd}=2.347$ RMSEA $=.06, \mathrm{CFI}=.94, \mathrm{GFI}=.91$, and $\mathrm{RMR}=.01$.

\subsubsection{General Self-Efficacy Scale (GSE)}

The General Self-Efficacy Scale was originally developed in Germany in 1979 by Jerusalem and Schwarzer, and adapted to Turkish by Aypay [33]. The scale consists of 10 items of four similar Likert types (sample item: knowing what to do when I encounter a new situation). Scholz and Schwarzer [34] found that, with a few exceptions, all items were between .30 and .77 , and alpha internal consistency coefficients were between .75 and .91 in item-total correlations calculated based on the data obtained using the 25 -fold version of the general self-efficacy scale. Confirmatory factor analysis results showed that the scale was a scale with single factor [34]. A study by Aypay [33] revealed a two-component structure with an eigenvalue greater than 1 emerged. Alpha internal consistency coefficients for scale components are .79 and .63. The calculated Alpha coefficient is .83.

In the conducted for this study, it was found that the scale was a scale with single factor and $48.01 \%$ of the variance explained while KMO value was found to be .90 and Cronbach's Alpha was .87 in the reliability study of the scale. The DFA results for validating the single-factor structure of GEFS showed that the goodness of fit index of the model was acceptable $\left(\chi^{2} / \mathrm{sd}=3.50\right.$, RMSEA $=.08, \mathrm{CFI}=.92$, GFI $=.92, \mathrm{RMR}=.01)$.

\subsection{Data Analysis}

In this research, firstly, information was given about the purpose of working on all participants of the implementation. The analysis of the data was conducted using SPSS 21 and AMOS programs. In the analysis of the data, the data set was examined in terms of error value, outliers, normality and multiple correlation. It was observed that there is no incorrectly entered data in this process. The relationship between variables was investigated by Pearson Product Moment Correlation Coefficient. T test was used to analyze the difference of football, basketball and handball referees' physical fitness, game knowledge, decision making, pressure, communication, REFS and GSE total scores according to 
gender variable. Multiple variance analysis (ANOVA) was used in the analysis of difference according to refereeing branch variable.

\section{Findings}

Comparison of Sub-dimensions of REFS, REFS and GSE total scores according to demographic variables is given in Table 1.

When Table 1 is examined, it can be seen that the levels of scores obtained by football, basketball and handball referees from REFS shows a significant difference according to gender variable. Therefore, referee self-efficacy levels of male referees are higher than of female referees. However, there is no significant difference in football, basketball and handball referees' physical fitness, pressure, communication and general self-efficacy levels compared to their genders.
ANOVA and LSD results of REFS Sub-dimensions, REFS and GSE total scores according to variable of refereeing branch are given in Table 2 .

When Table 2 is examined, a significant difference was found between REFS total scores of football, basketball and handball referees $[F(2,194)=4.08, p<.05]$, and physical fitness sub-dimension $[F(2,194)=9.61, p<.05]$ and refereeing branch. According to results of LSD test which was applied to determine which branch has such a difference, REFS scores of football and basketball referees are higher than of handball referees. Football referees obtained higher scores than handball referees and basketball referees obtained higher scores than football and handball referees in terms of physical fitness. It was found that football, basketball and handball referees' physical fitness, game knowledge, decision making, pressure, communication and REFS total scores did not show any significant difference compared to refereeing branch variable $(p>.05)$.

Table 1. T-test Results of Sub-dimensions of REFS, REFS and GSE Total Scores According to Gender

\begin{tabular}{|c|c|c|c|c|c|c|c|}
\hline \multirow{2}{*}{ Variables } & \multicolumn{2}{|c|}{$\begin{array}{l}\text { Female } \\
(n=19)\end{array}$} & \multicolumn{2}{|c|}{$\begin{array}{c}\text { Male } \\
(n=173)\end{array}$} & \multirow{2}{*}{$t$} & \multirow{2}{*}{$s d$} & \multirow{2}{*}{$p$} \\
\hline & $\bar{X}$ & $S$ & $\bar{X}$ & $S$ & & & \\
\hline Physical fitness & 21.59 & 3.50 & 22.47 & 2.46 & 1.61 & 193 & .10 \\
\hline Game knowledge & 13.44 & 1.57 & 13.87 & 1.39 & 1.45 & 193 & .14 \\
\hline Decision making & 13.25 & 1.31 & 13.72 & 1.45 & 1.57 & 193 & .11 \\
\hline Pressure & 13.85 & 1.56 & 13.81 & 1.50 & .11 & 193 & .90 \\
\hline Communication & 18.25 & 1.85 & 18.39 & 1.73 & .36 & 193 & .71 \\
\hline REFS total & 79.11 & 6.77 & 82.27 & 6.27 & 2.40 & 193 & $.01 *$ \\
\hline GSE total & 36.18 & 2.82 & 35.07 & 3.86 & 1.43 & 193 & .15 \\
\hline
\end{tabular}

$\mathrm{p}<.05^{*}$ 
Table 2. ANOVA and LSD Results of REFS Sub-dimensions, REFS and GSE Total Scores According to Refereeing Branch

\begin{tabular}{|c|c|c|c|c|c|c|c|c|c|c|c|}
\hline Variables & Group & $n$ & $\bar{X}$ & $S$ & $\begin{array}{l}\text { Source of } \\
\text { Variance }\end{array}$ & KT & $s d$ & KO & $F$ & $p$ & $L S D$ \\
\hline \multirow{5}{*}{ Physical fitness } & 1.Football & 99 & 22.33 & 2.47 & \multirow{2}{*}{$\begin{array}{c}\text { Between } \\
\text { groups }\end{array}$} & \multirow{2}{*}{123.09} & \multirow{2}{*}{2} & \multirow{2}{*}{61.54} & \multirow{5}{*}{9.61} & \multirow{5}{*}{$.00 *$} & \multirow{5}{*}{$\begin{array}{l}1-3 \\
2-1 \\
2-3\end{array}$} \\
\hline & 2 Backetbal & 56 & 2332 & 204 & & & & & & & \\
\hline & & & & & \multirow{2}{*}{$\begin{array}{l}\text { Within } \\
\text { groups }\end{array}$} & \multirow{2}{*}{1229.18} & \multirow{2}{*}{192} & \multirow{2}{*}{6.40} & & & \\
\hline & 3.Handball & 40 & 21.02 & 3.20 & & & & & & & \\
\hline & Total & 195 & 22.34 & 2.64 & Total & 1352.28 & 194 & & & & \\
\hline \multirow{5}{*}{ Game knowledge } & 1.Football & 99 & 13.81 & 1.35 & \multirow{2}{*}{$\begin{array}{c}\text { Between } \\
\text { groups }\end{array}$} & \multirow{2}{*}{9.01} & \multirow{2}{*}{2} & \multirow{2}{*}{4.50} & \multirow{5}{*}{2.23} & \multirow{5}{*}{.10} & \\
\hline & 2 Reckethol & 56 & 1407 & 17 & & & & & & & \\
\hline & 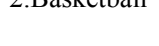 & 50 & 14.01 & 1.11 & \multirow{2}{*}{$\begin{array}{l}\text { Within } \\
\text { groups }\end{array}$} & \multirow{2}{*}{386.34} & \multirow{2}{*}{192} & \multirow{2}{*}{2.01} & & & \\
\hline & 3.Handball & 40 & 13.45 & 1.82 & & & & & & & \\
\hline & Total & 195 & 13.81 & 1.42 & Total & 395.35 & 194 & & & & \\
\hline \multirow{5}{*}{ Decision making } & 1.Football & 99 & 13.68 & 1.26 & \multirow{2}{*}{$\begin{array}{l}\text { Between } \\
\text { groups }\end{array}$} & \multirow{2}{*}{1.38} & 2 & 60 & & & \\
\hline & 2.Basketball & 56 & 13.73 & 1.43 & & & & & & & \\
\hline & & & & & Within & 400.27 & 192 & 2.08 & .33 & .71 & \\
\hline & 3.Handball & 40 & 13.50 & 1.76 & groups & & & & & & \\
\hline & Total & 195 & 13.66 & 1.43 & Total & 401.66 & 194 & & & & \\
\hline & 1.Football & 99 & 13.88 & 1.55 & Between & 520 & 2 & $261+2+$ & & & \\
\hline & 2 Basketball & 56 & 13.92 & 139 & groups & 5.22 & 2 & 2.01 & & & \\
\hline Pressure & & & & & Within & 437.49 & 192 & 2.27 & 1.14 & .32 & \\
\hline & 3.Handball & 40 & 13.50 & 1.55 & groups & & & & & & \\
\hline & Total & 195 & 13.82 & 1.51 & Total & 442.71 & 194 & & & & \\
\hline & 1.Football & 99 & 18.62 & 1.50 & Between & 1276 & 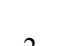 & 620 & & & \\
\hline & 2 Basketball & 56 & 1810 & 183 & groups & & & & & & \\
\hline Communication & & & & & Within & 578.90 & 192 & 3.01 & 2.11 & .12 & \\
\hline & 3.Handball & 40 & 18.12 & 2.09 & groups & & & & & & \\
\hline & Total & 195 & 18.37 & 1.74 & Total & 591.67 & 194 & & & & \\
\hline & 1.Football & 99 & 82.25 & 6.30 & Between & $226 \mathbf{s}$ & 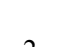 & 160,16 & & & \\
\hline & 2 Basketball & 56 & 8289 & 580 & groups & & & & & & \\
\hline REFS total & 3.Handball & 40 & 79.30 & 7.03 & $\begin{array}{l}\text { Within } \\
\text { groups }\end{array}$ & 7681.14 & 192 & 40.00 & 4.08 & $.01 *$ & $\begin{array}{l}1-5, \\
2-3\end{array}$ \\
\hline & Total & 195 & 81.84 & 6.42 & Total & 8008.07 & 194 & & & & \\
\hline & 1.Football & 99 & 35.40 & 3.67 & Between & 5601 & 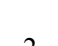 & 2048 & & & \\
\hline & 2 Basketbal & 56 & 3442 & 359 & grc & & & & & & \\
\hline GSE total & & & & & Within & 267715 & 192 & 1394 & 2.04 & .13 & \\
\hline & 3.Handball & 40 & 35.90 & 4.05 & groups & 2017.15 & 192 & 15.94 & & & \\
\hline & Total & 195 & 35.22 & 3.75 & Total & 2734.07 & 194 & & & & \\
\hline
\end{tabular}

$\mathrm{p}<.05^{*}$ 
The correlation between football, basketball and handball referees' total scores of sub-dimensions of REFS, REFS and GSE and age-refereeing experience is given in Table 3.

Table 3. The Correlation between Football, Basketball and Handball Referees' Total Scores of Sub-dimensions of REFS, Total Scores of REFS and GSE and Age-Refereeing Experience

\begin{tabular}{|c|c|c|c|}
\hline & $\mathrm{N}$ & Age & $\begin{array}{c}\text { Refereeing } \\
\text { experience }\end{array}$ \\
\hline Physical fitness & 195 & .05 & .04 \\
\hline Game knowledge & 195 & $.24 * *$ & $.23^{* *}$ \\
\hline Decision making & 195 & $.27^{* *}$ & $.23^{* *}$ \\
\hline Pressure & 195 & $.15^{*}$ & $.14^{*}$ \\
\hline Communication & 195 & $.19^{* *}$ & $.10^{*}$ \\
\hline REFS total & 195 & $.25^{* *}$ & $.19^{* *}$ \\
\hline GSE total & 195 & $.19^{* *}$ & .06 \\
\hline
\end{tabular}

$* * \mathrm{p}<.01, * \mathrm{p}<.05$

When Table 3 is examined, it is seen that there is a significant and positive relationship between football, basketball and handball referees', game knowledge, decision making, pressure, communication, REFS and GSE total scores and their ages. It was found the highest relationship is between decision making and age $(r=.27, p<.01)$, and the lowest one is between physical fitness and age $(r=.15, \mathrm{p}$ $<.01)$. When the obtained data are examined, it is seen that referees' game knowledge, decision making, pressure, communication, REFS and GSE total scores increase as the age increases. It was found no significant difference between football, basketball and handball referees' physical fitness sub-dimension scores and their ages $(p>.05)$. It was found a positive and significant difference between football, basketball and handball referees' game knowledge, decision making, pressure, communication, REFS total scores and refereeing years. The highest correlation was found between decision making and game knowledge $(r=.23, p<.01)$; and the lowest correlation was found between communication scores $(r=.10, p<.05)$. When the obtained data are examined, it is seen that football, basketball and handball referees' game knowledge, decision making, pressure, communication, REFS total scores increase as the year of refereeing increase. It was found no significant difference between football, basketball and handball referees' physical fitness sub-dimension and GSE total scores and their ages $(\mathrm{p}>.05)$.
Results of correlation between football, basketball and handball referees' total scores of sub-dimensions of REFS, REFS and GSE are given in Table 4.

In Table 4 showing relationship between the football, basketball and handball referees' physical fitness, game knowledge, decision making, pressure, communication, REFS and GSE total scores, it is seen that all the variables are positively and significant correlated to each other. In the relationship between and within referee self-efficacy sub-dimensions, while the highest correlation was between REFS total score and game knowledge $(r=.79, \mathrm{p}<.01)$, the lowest correlation was between communication and physical fitness $(\mathrm{r}=.25, \mathrm{p}<.01)$. When the relationship between the total score of GSE, and total score of REFS and REFS sub-dimensions is examined, it was found that the highest correlation between was REFS total score and GSE total score $(\mathrm{r}=.56, \mathrm{p}<.01)$ and the lowest correlation was between GSE total score and physical competency $(r=.29, \mathrm{p}<.01)$.

\section{Discussion}

Findings of the study showed that football, basketball and handball referees' totals scores of REFS show a significant difference according to gender. According to this, referee self-efficacy of male referees is higher than of female ones. However, there is no significant difference in football, basketball and handball referees' physical fitness, decision making, pressure, communication and general self-efficacy levels according to their gender. In the study conducted on basketball referees, Karaçam and Pulur [27] concluded that REFS total scores of male referees are higher than of female ones. Moreover, in parallel with the current study, Karaçam and Pulur [27] stated that there is no significant difference in basketball referees' physical fitness, pressure and communication levels according to their gender. In this context, results of the study show a compliance with the literature. On the other hand, in contrast to the study, Karaçam and Pulur [27] found a significant difference between physical fitness and decision making sub-dimensions in favor of male basketball referees. It is thought that this result obtained in physical fitness and decision making sub-dimensions is due to a special characteristic of study group.

Table 4. Correlation between Football, Basketball and Handball Referees' Total Scores of Sub-dimensions of REFS and Total Scores of REFS and GSE

\begin{tabular}{|c|c|c|c|c|c|c|c|}
\hline Variables & 1 & 2 & 3 & 4 & 5 & 6 & 7 \\
\hline 1. Physical Fitness & 1.00 & $.47^{* *}$ & $.31^{* *}$ & $.30^{* *}$ & $.25^{* *}$ & $.71^{* *}$ & $.29^{* *}$ \\
\hline 2. Game Knowledge & & 1.00 & $.61^{* *}$ & $.47^{* *}$ & $.46^{* *}$ & $.79^{* *}$ & $.47^{* *}$ \\
\hline 3. Decision Making & & & 1.00 & $.52^{* *}$ & $.49^{* *}$ & $.74^{* *}$ & $.49^{* *}$ \\
\hline 4. Pressure & & & & 1.00 & $.42^{* *}$ & $.68^{* *}$ & $.43^{* *}$ \\
\hline 5. Communication & & & & & 1.00 & $.68^{* *}$ & $.51^{* *}$ \\
\hline 6. REFS Total & & & & & & 1.00 & $.56^{* *}$ \\
\hline 7. GSE Total & & & & & & & 1.00 \\
\hline
\end{tabular}

$* * \mathrm{p}<.01$ 
No significant relationship is found between REFS scores of the football, basketball and handball referees and their gender. Karaçam and Pulur [27] also found no significant relationship between REFS scores of the basketball referees and their gender. In this context, results of the study show a compliance with the literature.

Research findings show that a significant difference was found between REFS total scores of football, basketball and handball referees, and physical fitness sub-dimension and refereeing branch. According to results of LSD test which was applied to determine which branches have such a difference, REFS scores of football and basketball referees are higher than of handball referees. Football referees obtained higher scores than handball referees and basketball referees obtained higher scores than football and handball referees in terms of physical fitness. In REFS total score, football and basketball referees obtained higher scores than handball referees. It is thought that the high scores of football and basketball referees on total scores of REFS and physical fitness are related to special characteristics of these branches. It was found that there is no study in the literature examining football, basketball and handball referees', physical fitness, game knowledge, decision making, pressure, communication and REFS and GSE total scores and refereeing branches. The research is thought to contribute to the field in this direction.

Research findings showed that there is a positive and significant difference between football, basketball and handball referees' game knowledge, decision making, pressure, communication, REFS and GSE total scores and their ages. It was found the highest relationship is between decision making and age, and the lowest one is between physical fitness and age. It was found no significant difference between football, basketball and handball referees' physical fitness sub-dimension scores and their ages. Myers et al. [23] and Karaçam \& Pulur [24-27] concluded that there is a positive and significant difference between game knowledge, decision making, pressure, communication, REFS and GSE total scores and age. In this context, results of the study show a compliance with the literature. It is thought that this result obtained in physical fitness sub-dimension is due to a special characteristic of study group. Aypay [33] and Karaçam \& Pulur [24-27] found that there is a positive and significant relationship between GSE total scores and age, which is a similar result with the current study. In this context, results of the study show a compliance with the literature. These results can be interpreted in a way that football, basketball and handball referees' game knowledge, decision making, pressure, communication, total REFS and GSE scores increase as their ages increase.

Research findings revealed a positive and significant difference between football, basketball and handball referees' game knowledge, decision making, pressure, communication, REFS total scores and refereeing years. The highest correlation was found between decision making and game knowledge; and the lowest correlation was found between communication scores. However, it was found no significant difference between football, basketball and handball referees' physical fitness sub-dimension and GSE total scores and their ages. Myers et al. [23] and Karaçam \& Pulur [24-27] concluded that there is a positive and significant difference between game knowledge, decision making, pressure, communication, REFS total scores and refereeing years. Guillén and Feltz [8] stated that refereeing experiences of referees have an impact on their self-efficacy. In this context, results of the study show a compliance with the literature. These results can be interpreted in a way that football, basketball and handball referees' game knowledge, decision making, pressure, communication and REFS total scores increase as refereeing year increases. On the other hand, Karaçam \& Pulur [24-27] found a positive and significant difference between physical fitness and GSE total scores and refereeing year. It is thought that this result obtained in physical fitness sub-dimension and GSE total score is due to a special characteristic of study group.

Relationships between the football, basketball and handball referees' physical fitness, game knowledge, decision making, pressure, communication, REFS and GSE total scores are examined, it is seen that all the variables are positively and significant correlated to each other. In the relationship between and within referee self-efficacy sub-dimensions, while the highest correlation was between REFS total score and game knowledge, the lowest correlation was between communication and physical fitness. When the relationship between the total score of GSE, and total score of REFS and REFS sub-dimensions is examined, it was found that the highest correlation between was REFS total score and GSE total score and the lowest correlation was between GSE total score and physical competency. Similarly, Myers et al. [23] and Karaçam \& Pulur [24-27] revealed that all the variables positively and significantly correlated each other when they examined the relationships between the football, basketball and handball referees' physical fitness, game knowledge, decision making, pressure, communication, REFS and GSE total scores. Moreover, Karaçam \& Pulur [24-27] examined the relationship between total score of GSE, and total score of REFS and REFS sub-dimensions and found a positive and significant relationship. In this context, results of the study show a compliance with the literature. These results can be interpreted in a way that football, basketball and handball referees' physical fitness, game knowledge, decision making, pressure, communication, REFS and GSE total scores influence each other positively.

\section{Conclusions}

As a result of the study, it was concluded that gender of football, basketball and handball referees is a significant variable in favor of male referees in terms of REFS total score levels. It was revealed that REFS total scores of football and basketball referees are higher than of handball 
referees. In physical fitness sub-dimension, it was concluded that scores of football referees are higher than of handball referees; and scores of basketball referees are higher than of handball referees. It was found a positive and significant relationship between football, basketball and handball referees' game knowledge, decision making, pressure, communication, REFS and GSE total scores and their ages. It was also found a positive and significant relationship between football, basketball and handball referees' game knowledge, decision making, pressure, communication, REFS total scores and their refereeing experience. Finally, it was revealed that football, basketball and handball referees' physical fitness, game knowledge, decision making, pressure, communication, REFS and GSE total scores influence each other positively.

\section{Suggestions}

1. In this study, the relationship between referee self-efficacy and general self-efficacy of football, basketball and handball referees was discussed. Examination of the different variables that are expected to influence referee self-efficacy of football, basketball and handball referees will contribute to the field.

2. When the training processes of football, basketball and handball referees are planned, the work for the improvement of referee self-efficacy and the general self-efficacy of referees may contribute to the performance of them.

3. In this study, the referee self-efficacy and general self-efficacy of football, basketball and handball referees were handled at the cognitive level. Studies to be made may contribute to the field.

4. This work is limited to football, basketball and handball referees. Implementation of studying to include different referee groups may contribute to the field.

\section{REFERENCES}

[1] A. Bandura. Self-efficacy: The exercise of control. New York: Freeman, 1997.

[2] D.L. Feltz, S.E. Short, P.J. Sullivan. Self-efficacy in sport. Champaign, IL: Human Kinetics, 2008.

[3] A. Bandura. Self-efficacy: Toward a unifying theory of behavioral change. Psychological Review, 84 (2), 191-215, 1977.

[4] A. Bandura. Social foundations of thought and action: A social cognitive theory. Englewood Cliffs, NJ: Prentice-Hall, 1986.

[5] F. Yıldırım, İ. Ö. İlhan. Reliability and validity study of Turkish version of general self-efficacy. Turkish Journal of Psychiatry, 21 (4), 301-308, 2010.
[6] C. Tuero, B. Tabernero, S. Marquez, F. Guillen. Análisis de los factores que influyen en la práctica del arbitraje [Analysis of the factors affecting the practice of refereeing]. SCAPE, 1(1), 7-16, 2002.

[7] A. Karaçam A. Pulur. Identification the Relation between Active Basketball Classification Referees' Empathetic Tendencies and Their Problem Solving Abilities. Universal Journal of Educational Research, 4, 1912 - 1917, 2016.

[8] F. Guillén, D. L. Feltz. A conceptual model of referee efficacy. Frontiers in psychology, 2, 25, 2011.

[9] R. Ekmekçi. Determining the source and coping style of stress among basketball referees and developing preventative administrative practices (Unpublished doctoral dissertation). Abant İzzet Baysal University, Bolu, 2008.

[10] B. Jackson, M.R. Beauchamp, P. Knapp. Relational efficacy beliefs in athlete dyads: An investigation using actor-partner interdependence models. Journal of Sport \& Exercise Psychology, 29, 170-189, 2007.

[11] S.E. Moritz, D.L. Feltz, K.R. Fahrbach, D.E. Mack. The relation of self-efficacy measures to sport performance: a meta-analytic review. Research Quarterly for Exercise and Sport, 71, 280-294 PubMed, 2000.

[12] J. J. Martin, D. L. Gill. The relationships among competitive orientation, sport-confidence, self-efficacy, anxiety, and performance. Journal of Sport and Exercise Psychology, 13(2), 149-159, 1991.

[13] R. Cengiz. The Relationship Between Self-Efficacy Levels and Leadership Qualities That Taekwondo Athlete Perceive. e-Journal of New World Sciences Academy, 7(4), 2B0089, 2012.

[14] D.L. Feltz, C.D. Lirgg. Perceived team and player efficacy in hockey. The Journal of Applied Psychology, 83, 557-564, 1998.

[15] K.S. Spink. Group cohesion and collective efficacy of volleyball teams. Journal of Sport \& Exercise Psychology, 12, 301-311, 1990.

[16] H. Öcal, O. Aydin. The relationships of collective efficacy beliefs, self efficacy beliefs and group cohesiveness with success evaluations and expectancies in sports teams. Journal of Faculty of Letters/Edebiyat Fakultesi Dergisi, 26(2), 2009.

[17] D.L. Feltz, M.A. Chase, S.E. Moritz, P.J. Sullivan. A conceptual model of coaching efficacy: Preliminary investigation and instrument development. Journal of Educational Psychology, 91, 765-776, 1999.

[18] R. T. Gençer, O. Kiremitçi, H. Boyacıoglu. Psychometric properties of coaching efficacy scale: A study on Turkish coaches. Sport Sciences, 4(2), 143-153, 2009.

[19] D.L. Feltz. A path analysis of the causal elements in Bandura's theory of self-efficacy and an anxiety-based model of avoidance behavior. Journal of Personality and Social Psychology, 42, 764-781, 1982.

[20] R.W. Lent, F.G. Lopez. Cognitive ties that bind: A tripartite view of efficacy beliefs in growth-promoting relationships. Journal of Social and Clinical Psychology, 21, 256-286, 2002.

[21] K.S. Spink. Collective efficacy in the sport setting. International Journal of Sport Psychology, 21, 380-395, 1990. 
[22] S.E. Short, P.S. Sullivan, D.L. Feltz. Development and preliminary validation of the collective efficacy questionnaire for sports. Measurement in Physical Education and Exercise Science, 9, 181-202, 2005.

[23] N. D. Myers, D. L. Feltz, F. Guillén, L. Dithurbide. Development of, and initial validity evidence for, the Referee Self-Efficacy Scale: A multistudy report. Journal of sport and Exercise Psychology, 34(6), 737-765, 2012.

[24] A. Karaçam A. Pulur. Adaptation study of referee self-efficacy scale (REFS) to Turkish. Journal of Physical Education and Sports Sciences, 11(1) 118-128, 2017.

[25] T. Farshad, M. R. Esmaeili, R. Bavandpour. "The effect of self-efficacy on job satisfaction of sport referees." European Journal of Experimental Biology 3.2: 219-225, 2013.

[26] T. J. Hepler, D. L. Feltz. Take the first heuristic, self-efficacy, and decision-making in sport. Journal of Experimental Psychology: Applied, 18(2), 154, 2012.

[27] A. Karaçam A. Pulur. Examining the Relationship between Referee Self-Efficacy and General Self-Efficacy Levels of Basketball Referees in Terms of Certain Variables. Journal of Education and Training Studies, Vol. 5, No. 8, 2017.
[28] N. Senemoğlu. Development, learning and instruction. Ankara: Gazi, 2000.

[29] A. L. Zeldin, S. L. Britner, F. Pajares. A comparative study of the selfefficacy beliefs of successful men and women in mathematics, science, and technology careers. Journal of Research in Science Teaching, 45(9), 1036-1058, 2008.

[30] A. Bandura. On the functional properties of perceived self-efficacy revisited. Journal of Management, 38(1), 9-44, 2012 .

[31] J. R. Fraenkel, N. E. Wallen.. How to design and evaluate research in education (7th ed.). New York: McGraw-Hill, 2009.

[32] Ş. Büyüköztürk. Scientific research methods (5th edition). Ankara: Pegem Academy, 2010.

[33] A. Aypay. Genel öz yeterlik ölçeği'nin GÖYÖ Türkçe'ye uyarlama çalışması. İnönü Üniversitesi Eğitim Fakültesi Dergisi, 11(2), 2010.

[34] U. Scholz, R. Schwarzer. The general self-efficacy scale: Multicultural validation studies. The Journal of Psychology, 139 (5), 439-457, 2005. 